This exhibition, curated by the Family Ties Network, connects with the themes of the conference Picturing the Family: Media, Narrative, Memory at Birkbeck, University of London, 10 and 11 July 2014.

http://www.bbk.ac.uk/brakc/conference.htm

Events associated with the exhibition at the Peltz Gallery and Birkbeck Cinema, both at 43 Gordon Square.

5 July 2014, 2:00-5:30pm: Artists' talk plus short film screening:

Suze Adams, Communion, 2012, 12

Rosy Martin, Too Close to Home? 1999, 8

Rosy Martin, The Sitting Room, 2002,

Sally Waterman, Wisdom, 2013, 1'25

Sally Waterman, Against, 2014, 5

25 July 2014, 6.30 - 8.30pm On the Border (Lizzie Thynne, 56', 2012):

Film screening plus $q$ and a with the director

Chair: Silke Arnold-de Simine, Senior Lecturer in Memory and Cultural Studies, Birkbeck

A daughter's exploration of her Finnish family's history prompted by the letters, objects, and photographs left in her mother's apartment. Fragmented memories, dreams, and diary entries are juxtaposed with the director's journey to significant places and people in that history from during and after the Russo-Finnish wars, $1939-1944$.

The Family Ties Network is a research group of artists, filmmakers and writers who explore memory, space, place and the family. Through events, conferences, exhibitions and publications, they aim to investigate a range of issues, encompassing the representation of family memories, the family album, oral history, bereavement, displacement, estrangement and home.

For further information:

http://familytiesnetwork.wordpress.com/exhibitions/

Sisterhood and After: The Women's Liberation Oral History Project, funded by the Leverhulme Trust, was produced by The Centre for Life Writing and Life History,

Sussex University in partnership with the British Library and the Women's Library.

Cover image: Rosy Martin with Kay Goodridge Acts of Reparation, 2006 Exhibition leaflet design by Jaime Huxtable

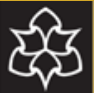

Birkeck

Manchester University University
of Sussex
THEGLASGOW
SCHOOL:
Family Ties: Re-framing Memory
An exhibition by the Family Ties Network

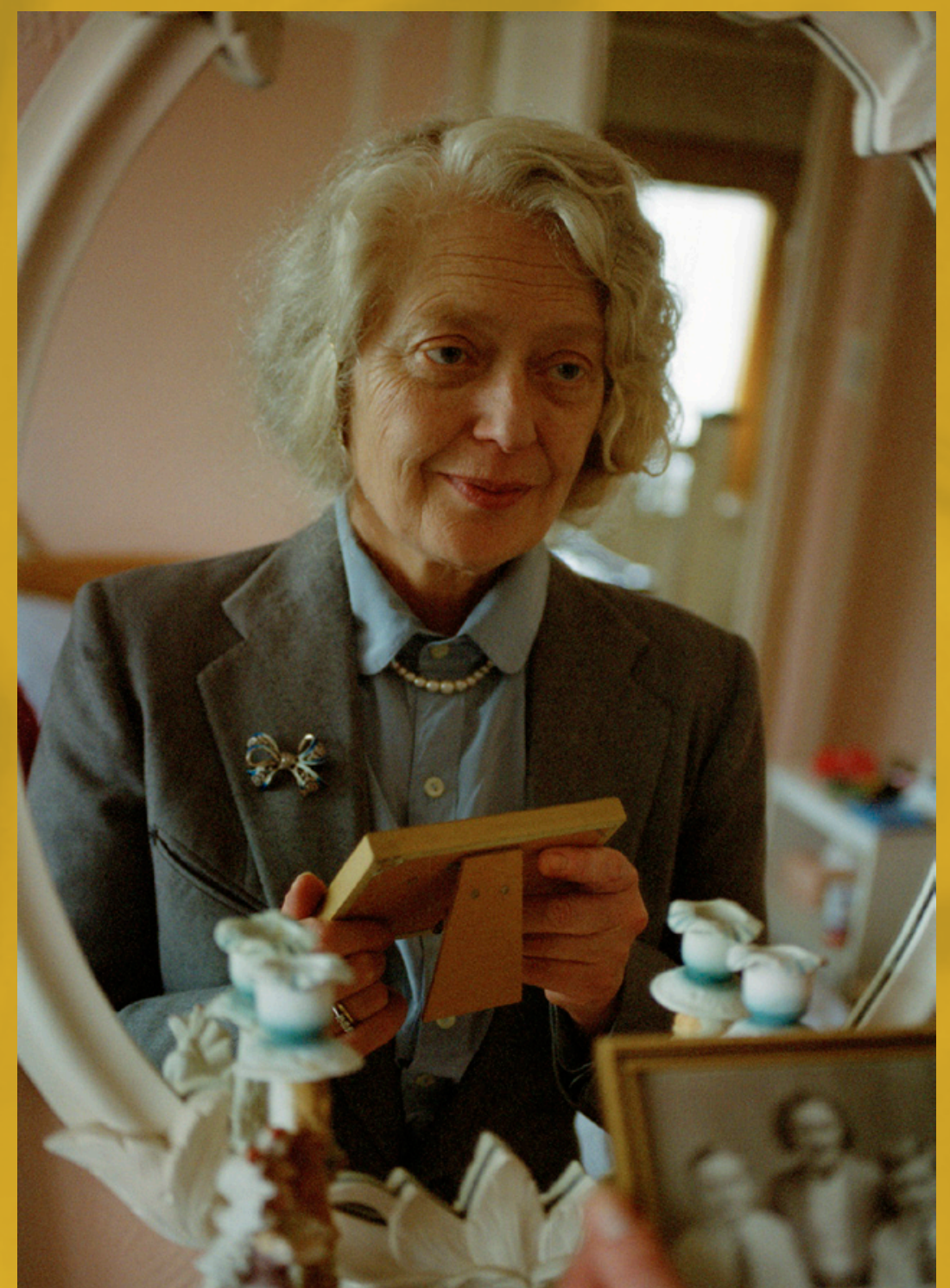

3 July - 25 July 2014 Free Entry
The Peltz Gallery, Birkbeck School of Arts, 43 Gordon Square, London WC1H OPD Monday-Friday, 10-7pm 
Family Ties: Re-framing Memory

How might we read memory in relation to the family and how can we enact these memories through art practice? This group exhibition explores the bittersweet aspects of reflective nostalgia, yet also considers the conflicts and contradictions inherent in acts of remembering.
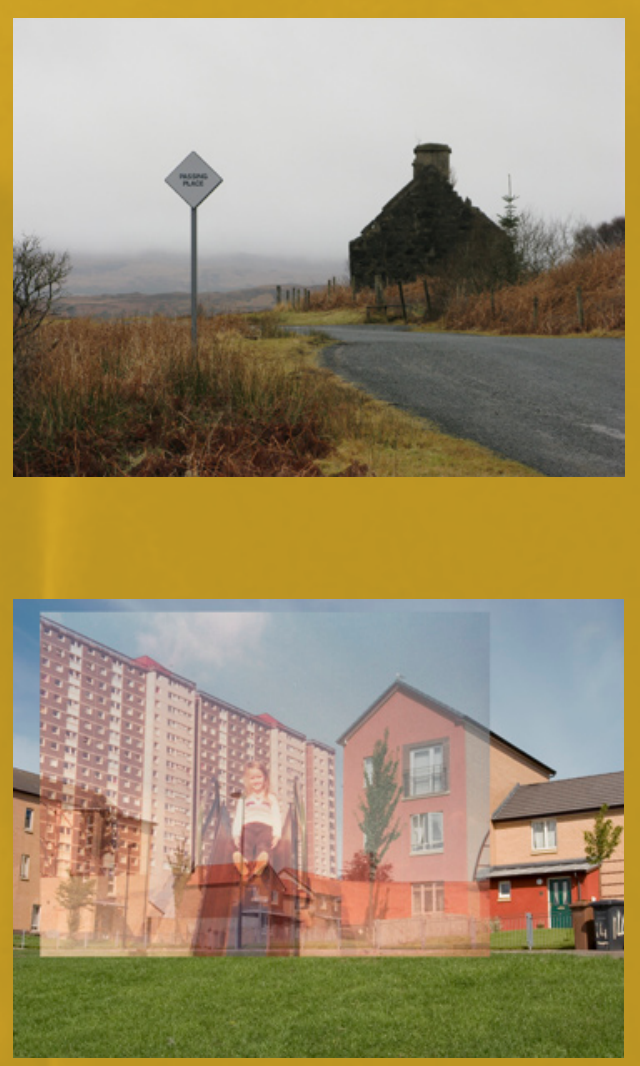

\section{Suze Adams}

Generation

Over the years Adams has been exploring Mull and making artworks that examine her ancestral provenance on the island, all the while pondering the divide between fact and fiction. Looking through old photo-albums, listening to family stories, visiting Mull Museum and observing the rhythms of the island, Adams has made fresh discoveries and conjured
in her mind further images, places and people. In in her mind further images, places and people. In to collective memory, asking: just how might the experiences of her extended family speak to others in ways that they might relate to their own family histories?

\section{Nicky Bird}

Beneath the Surface / Hidden Place

The four photographs in this show are from Bird's larger series Beneath the Surface / Hidden Place (2007-2010), commissioned by Stills, Edinburgh. The series explored the physical and emotional effects of economic change and regeneration in Scotland. Bird worked in four locations in close collaboration with individuals and communities who took her to the spot where a 'family' photograph was originally taken so that the new photographs of place are informed by the whe collaborators personal histories despite their physical erasure from the local landscape. Free copies of the project publication, funded by the Kraszna-Krausz-
Foundation in 2010 , are available during the exhibition.

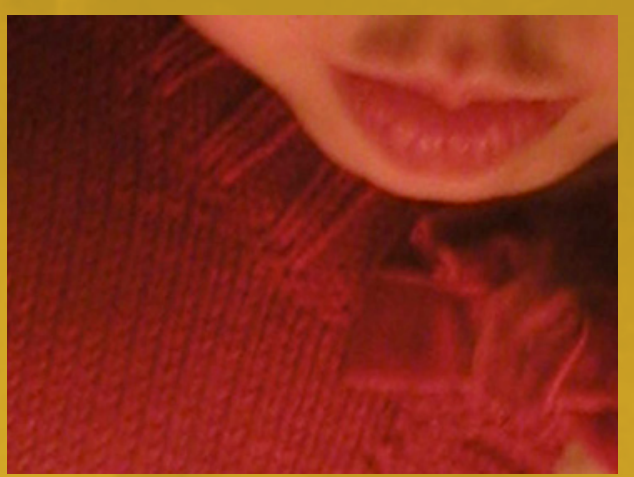

Jacqueline Butler

The Other Side of Wonderland: 12 Backgrounds The title alludes to reflections on a collection of photographs covering the first twelve years of the artist's daughter's life. Using Butler's family album and Charles Dodgson ('Lewis Carroll')'s photographs held at the National Media Museum, the work suggests shadows of past lives and encourages the discovery of past selves. It seeks to revive something of the "astonishing being", as Bachelard describes it in The Poetics of Reverie, setting in motion a yearning for a place that escapes measured time and to understand the reverie of childhood.

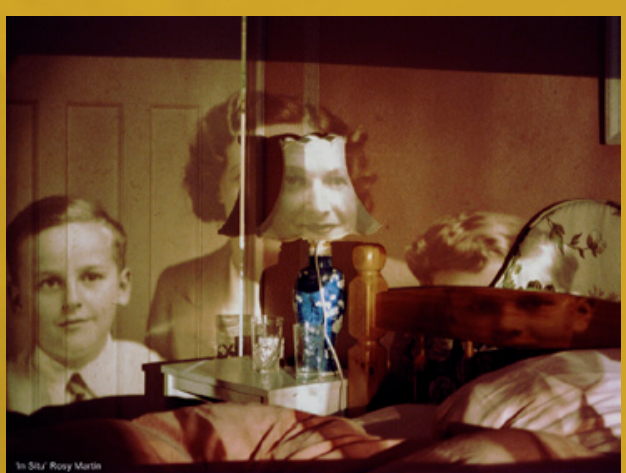

Rosy Martin

In Situ and Acts of Reparation

Martin's work explores bereavement, grief and mourning. Alone in the home she grew up in after her mother's death, it was as if her parents haunted this theatre of memories. The series In Situ (20061938/9) makes this feeling visible in projecting significant family photographs upon these too familiar surfaces. Printed on gossamer fine silk, soft and delicate, these ghostly forms shimmer like memories themselves. In Acts of Reparation (2006), Martin embodies both of her parents re-imagining a lost past through phototherapeutic re-enactments. In these transformative acts of performing another, she reconsidered the complexities and contradictions of their lives with a gentler perspective, inflected with loss.

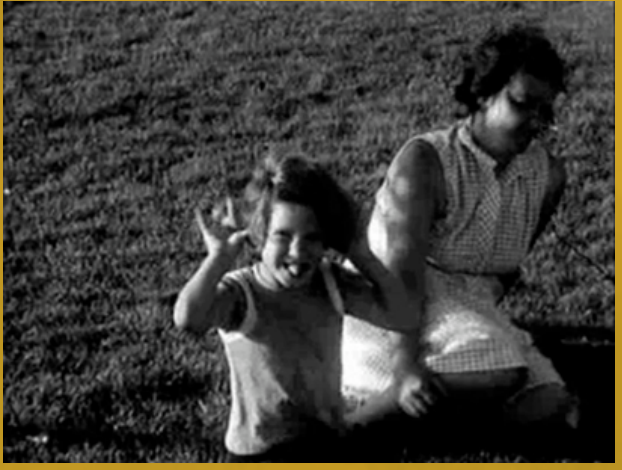

\section{Lizzie Thynne}

Voices in Movement

Sound work with images, 15

Composer: Ed Hughes,

Producer: Margaretta Jolly

This sound-led work draws on memories recorded for Sisterhood and After: The Women's Liberation Oral History Project. Thynne experiments with bringing these stories together to evoke collective, yet also diverse, perspectives. Barbara Taylor and Barbara Jones' childhood recollections are followed by a montage of other women's shifting views of the by a montage of other women's shifting views of the
family as they got involved in feminist politics. Fleeting family as they got involved in feminist politics. Fleeting
archival images are glimpsed only to disappear, mimicking the process of memory itself. http://www. bl.uk/learning/histcitizen/sisterhood/about.html

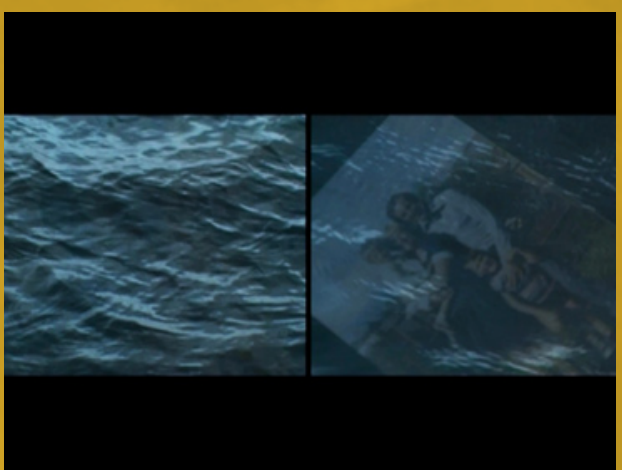

Sally Waterman
The Deep Sea Swell

1'30"

Waterman re-interprets T. S Eliot's poem 'The Waste Land' to retrieve repressed memories of conflict and separation arising from her parents' marital breakdown and divorce. The video, The Deep Sea Swell (2009), meditates on her past, constructing a multi-layered narrative to represent her estrangement from her father as well as the darker undercurrents from a buried past that continue to resurface. 